\title{
Do We Need a Normative Account of the Decision
}

\author{
to Parent?
}

\author{
Dr Leslie Cannold
}

Centre for Applied Philosophy and Public Ethics

Working Paper Number 2002/4

Centre for Applied Philosophy and Public Ethics (CAPPE)

\section{CAPPE Melbourne}

Department of Philosophy University of Melbourne

Parkville, Victoria, 3010

Phone: (03) 9344-5125

Fax: (03) 9348-2130

\section{CAPPE Canberra}

GPO Box A260

Australian National University

Canberra, 2601

Phone: (02) 6125-8467

Fax: (02) 6125-6579

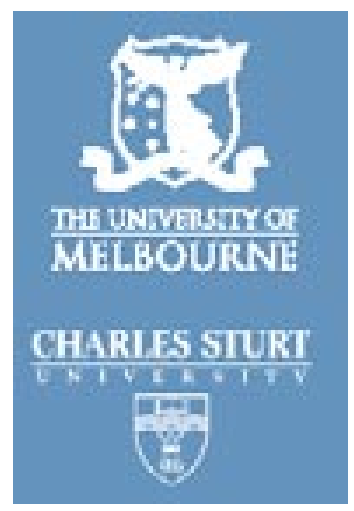




\section{Do We Need a Normative Account of the Decision to Parent?}

ACKNOWLEDGMENTS: This paper was read at a staff seminar at the Centre for Applied Philosophy and Public Ethics and benefited from the comments of all those present. Special thanks go to Janna Thompson for reading and commenting on several drafts.

ABSTRACT: This paper provides an analysis of several philosophically interesting results of a recent study of the fertility decision-making of thirty-five childless/childfree Australian and American women. While most women endorsed and expanded on longstanding normative prescriptions for how a "good" mother ought to feel and behave, they were at a loss (at times quite literally) to explain why a woman should decide to mother in the first place. For several women, this difficulty led them to conclude that a decision to have a child was "irrational." । argue that applied philosophers bear some causal and moral responsibility for women's negative conclusions about the rationality of deciding to mother and are obligated to respond to these findings by beginning work on normative accounts of the decision to parent. Suggestions are made about what such accounts should include, and avoid, to ensure relevance to women and acceptability to both feminist and non-feminist philosophers. 


\section{Do We Need a Normative Account of the Decision to Parent?}

This paper provides an analysis of several philosophically interesting results of a recent study of the fertility decision-making of thirty-five childless/childfree Australian and American women. While most women endorsed and expanded on longstanding normative prescriptions for how a "good" mother ought to feel and behave, they were at a loss (at times quite literally) to explain why a woman should decide to mother in the first place. For several women, this difficulty led them to conclude that a decision to have a child was "irrational." The circumstances women nominated as constraining their freedom to choose motherhood included their difficulty in forming and/or maintaining stable relationships with suitable partners or partners willing to have children, and the conflict many anticipated between motherhood and their employment needs and aspirations. Similar conclusions about the extrinsic constraints on women's childbearing decisions, and thus the difficulty at times of distinguishing between voluntary and involuntary childless/childfreeness, have been drawn from large population-based studies of women's fertility decision-making. ${ }^{1}$ The data also suggested that women's freedom to choose motherhood was constrained by the lack of a contemporary normative framework that explains why a decision can be rational, and the increasingly currency of normative accounts of the decision to remain childfree. I argue that applied philosophers bear some causal and moral responsibility for women's negative conclusions about the rationality of deciding to mother and are obligated to respond to these findings by beginning work on normative accounts of the decision to parent. Suggestions are made about what such accounts should include and avoid in order to be relevant to women and acceptable to both feminist and non-feminist philosophers.

After briefly presenting the findings regarding good motherhood prescriptions, the reasons women do and don't find "good" or 'right" ones for mothering and why some women characterise a decision to have children as "irrational," I will seek to answer four questions. 
Firstly, what explains why so many of the women in the study believed that there were few "good/right" reasons to have a child, and why several consequently believed that a decision to mother was "irrational"? Secondly, how did the women define "good/bad," "right/wrong" and "rational/irrational," and how do their understandings accord with various philosophical and ethics understandings of these terms? Thirdly, why should philosophers be concerned about some women's negative conclusions about the rationality of deciding to mother? Fourthly, what might a normative account of the decision to parent, acceptable to both feminist and non-feminist philosophers, include and avoid?

\section{THE STUDY}

The research that forms the basis of this paper was undertaken as the basis for my $\mathrm{PhD}$ dissertation. It comprised extended interviews with 35 fertile childless/childfree Australian and North American women, aged 28 to 42 . The study was primarily concerned to investigate whether women described their childless/childfreeness as "chosen," and if so whether that description was a good "fit" with everyday understandings of choice. ${ }^{2}$ It took place against the backdrop of rates of Australian and North American childlessness/childfreeness projected to reach 28 per cent and 22 per cent respectively among women currently in their fertile years. ${ }^{3}$

\section{CHILDLESS/CHILDFREE/CHILDFREE WOMEN CONCUR WITH AND EXPAND ON EXISTING “GOOD” MOTHERHOOD REQUIREMENTS}

Since the 1970s, feminist literature and empirical research has explored and critiqued the expansive and often unrealistic expectations society at large and mothers themselves often have about how the experience of motherhood ought make them feel and how, as mothers, they ought to feel and act towards their children. ${ }^{4}$

The "good" motherhood requirements that Australian and North American have articulated since the 1970s and with which the childless/childfree/childfree women in the study concurred were that "good" mothers should be responsible and consistently provide their children with unconditional love, patience and nurture. Some of the childless/childfree/childfree women in 
the study endorsed other longstanding "good" motherhood requirements, like always putting her children's needs first and fulfilling her young children's needs to have her in "constant attendance."

Moreover, childless/childfree women expanded on the requirements of "good" motherhood. For them, a good mother was one who had children in the context of a stable (for some women heterosexual and married) relationship, who was financially and emotionally stable and who had her children at the "right" age, with the "right" partner and at the "right" point in her relationship. She was also a woman who was enthusiastic about having and raising a child, and had made a deliberate and serious decision to become a mother. These findings affirm conclusions I drew in my previous research into women's reproductive decision-making that "good" motherhood standards impact both on women's experiences and understandings of motherhood and on the decision-making process of women considering motherhood. ${ }^{5}$

\section{CHILDLESS/CHILDFREE/CHILDFREE WOMEN SPONTANEOUSLY ARTICULATE "BAD/THE WRONG," BUT FIND IT DIFFICULT TO ARTICULATE "GOOD/RIGHT" OR "RATIONAL" REASONS FOR HAVING CHILDREN}

Women in the study provided a wide range of explanations for their desire/decision to have children ${ }^{6}$. These were the desire for the responsibility and commitment children require, the desire to take risks and to face new life challenges, to satisfy and/or to keep their partner, to fulfil their (positively-viewed) imagined future as a mother, to guard against loneliness, to love and to be loved by a child, to confirm their femininity and adulthood, to remain "in-step" with their peers, to avoid loneliness to affirm existing relationship bonds (like those with their own mothers) and to find existential meaning and fulfilment in their lives. ${ }^{7}$ They also supplied a number of reasons for wanting or deciding to be childless/childfree. These were the fear of and desire to avoid the all-encompassing nature of maternal responsibility and commitment, the fact that children are hard work and women's work, an unwillingness to parent with out (currently lacking) husband or family support, the desire to remain at the centre of and in control of their emotional and/or working lives and the irreversibility of the childbearing decision (the fear of being "trapped"). ${ }^{8}$ 
Women spontaneously ${ }^{1}$ characterised certain reasons - their or ones cited by others' - for having children as "bad/wrong" or "good/right" ones. Thus, not only did the childless/childfree/childfree women in the study believe that a "good" mother ought to make a deliberate and serious decision to have a child, they thought she ought make that decision for reasons that were "good/right" ones rather than ones that were "bad/wrong." This normative of reproductive decision-making accords well with that proposed by Gibson in her 1995 Journal of Applied Philosophy article "Reasons for Having Children: Ends, Means and 'Family Values'”. Gibson argues that the possibility of reproductive choice makes an individual's reasons for having children relevant to the question of the morality of that decision. In addition, she argues that people are both causally and morally responsible for what they decide. $^{9}$

However, while women did spontaneously offered both negative and positive value judgements of their own or other women's reasons for having children, they were far more likely to proffer "bad/wrong" reasons for having children than they were to suggest "good/right" ones. Even when asked (in response to an assertion that a particular childbearing reason was "bad/wrong," to articulate a "good/right" reason for having kids) women found it difficult. As a consequence of these difficulties, several women described a decision to have children as "irrational."

\section{“BAD/WRONG” AND “GOOD/RIGHT” REASONS TO HAVE CHILDREN}

Nearly half the sample (seventeen women) spontaneously offered eleven "bad/wrong" reasons for having children. Many of these are clearly related to the extended "good" motherhood requirements to which childless/childfree/childfree subscribe. For instance, Lorne's belief that it is wrong for women to have children for trivial lifestyle reasons is just the flip side of the requirement that "good" mothers make a "serious" decision to have a child. The

\footnotetext{
${ }^{1}$ The interview protocol did not require women be asked for their assessment of any reason they or others had for deciding to have children.
} 
eleven reasons women nominated as "bad/wrong" reasons for having children were: when you don't really want them; to quell boredom; to remedy dissatisfaction at work; to do what everyone else is doing (stay "in-step"); because time is running out; to avoid loneliness in old age; to hold a relationship together; to adhere to female socialisation to mother; to experience pregnancy; to have a child to satisfy one's own needs without adequate consideration of the child's need. An example of this latter reason was Laney's view tht it would be wrong for her to have a child to fulfil her own need to give:

\footnotetext{
...For many years I had this fantasy that I would have kids, and hadn't really worked out why. Why I had this desire to have kids and I think that a lot of it was around me rather than the kids. So it was for my needs rather than a child's needs.

Q: And what where those needs?

Mine? Around filling the hole that I felt was in my life. And, this will sound corny, like I have so much to give. And I thought that was what I wanted...to have this thing in my life that belonged to me, that would fill this hole, whatever. I don't think they're the right reasons... It's like trying to sort myself out by doing something with a child: my needs, rather than the child's needs...
}

Three women offered, sometimes with some difficulty, three "good/right" reasons for having children: because it is an extension of you and your partner; to raise good citizens and; to create someone who will be a real part of your life.

\section{Motherhood as an "Irrational," and Childlessness/Childfreeness as a "Rational" Decision}

From their belief that there were few good/right reasons to have children and many good/right reasons not to have them, several women drew the conclusion that a decision to mother was "irrational." The discomfort women felt making considered but irrational decisions about motherhood led them to understand their own and other women's desire to parent as the result of the overpowering demands of their biological selves: biological demands that were, according to their definitions, beyond the pull of reason. 
Barbara's struggle to think of any good reasons to have children, and the ease with which she

can produce "rational" reasons not to, has led her to conclude that her and other women's

desires to mother are the result of a strong but resistible physical "urge":

It terrifies me that you make a choice in life that then immediately sets off a whole chain of events that then limits your choice. That if I had a child, could I then not pursue my career - stuck! Trapped!...I hate the idea of being trapped. Of making choices that are not reversible...I know that if I had a child my first responsibility would be to the child and not myself and that's the deal...Now in my work l've always put my clients first, my clients come before my husband, my personal time, my private life, my recreation. It's a responsibility. But I can always manage that responsibility. You know, I can cancel the appointment. But with a child, you can't...It has occurred to me that this urge to have children is a physical thing. Men don't have it... Well look, if women didn't have a maternal urge, why would you have a baby? Why would you?

Q: ...So what does that make you then, somebody who hasn't decided to follow that maternal urge?

Someone who regards the bringing of children into the world as something you really need to consider very carefully from a rational perspective: about how that fits into your life, your lifestyle and your life choices as opposed to, "I want a baby." Because I honestly think most women want a baby. And it's an all consuming urge to have a baby...And I don't think women think, "I won't have a good night's sleep for years. I will never have a weekend alone with my husband again. I will have to compromise in my work...I'll never go to a folk concert again...I can't just go out whenever." Women don't think about it.

Q: Do you think they should?

Yes! Absolutely!

Sharon experiences her newfound desire to have children as biological because of what she sees as the irrationality of a decision to have children and the rational grounding of her previous pro-childless/childfreeness position:

So now I'm in a pretty stable de facto relationship with a guy and I really want to have kids. It's amazing.

Q: Why have you [experienced it] like that?

Because, if I look at it really rationally, I say having kids is going to screw up my comfortable existence. I've got a very comfortable existence. And it really puts paid to lots of notions of career. There's careers you can have with children, but it's tough going and there's a limit. And the world is definitely not equal out there for men and women in the business world, especially for women with kids. It's just really a hard juggling act and I see it with people I work with and I just think it's dreadful.

Q: What kind of things do you see? 
Oh, just conflicting demands between jobs. I'm in a job where I work fifty to sixty hours a week. And people trying to bring up young kids and work at the same time. And you have to be there at work, otherwise you're not being serious. But you know, with young kids, there's this guilt that you should be spending more time with the kids...Yeah, so on that rational level, it's making a decision that goes forever. I don't usually make decisions like that. And physically it's hard, and financially it's hard. You can think of a whole heap of reasons why not. And I'll write a list of pros and cons. And there are masses and masses and masses of cons. And the pros are like, "Well, I want to." It's like, come on, you're intelligent, you must be able to think of some good reasons here...

Q: What do you think is a good reason?

Well, because I want to. I'm trying to break that down into why, and that's where I come back to, I think it's a sort of biological thing...it's physical or it's emotional... It's really hard for me to say [why I want them]. There are these emotional, irrational reasons for having kids that are actually much stronger than the rational ones.

\section{ANSWERING THE FOUR QUESTIONS}

Q1: What explains why so many of the women in the study believed that there were few "good/right" reasons to have a child, and why several consequently believed that a decision to mother was "irrational"?

The study confirmed the findings of previous research demonstrating that most contemporary women of childbearing age see motherhood as a "choice" rather than a "mandate". Arguably, this view is at least in part a consequence of the success of second-wave feminism in redefining social norms around motherhood. Indeed, Kaplan sees the changes in women's attitudes, self-definitions and expectations as the one exception to the otherwise "meagre harvest" of Australian feminist activism. ${ }^{11}$ All the women in the study believed that womanhood did not equal motherhood, by which they seemed to mean that they did not believe that motherhood was intrinsic to female identity and hence that all women must mother and childless/childfree women were deviant.

However, along with an understanding of motherhood as a choice has come the belief, one consistent with some philosophical accounts of how childbearing decisions are and ought to be made, that one needs "good/right" reasons for choosing it ${ }^{12}$. The lack of such reasons made a decision to mother "irrational" and women's childbearing and rearing activities 
explicable only as "natural" rather than "'distinctly human" events. ${ }^{13}$

Why did the women in the study find it so easy to arrive at "bad" reasons for becoming a mother, and so difficult to come up with "good/right ones? One explanation starts from the observation that bad/wrong reasons had two characteristics; they were ones that were motivated by trivial or solely self-oriented ("selfish") desires and/or they were ones that saw children as a means to a woman's ends, regardless of what those ends were. Many women condemned trivial or self-oriented reasons for having children like the desire to "dress them up" or to "avoid loneliness in old age". However, in addition, some condemned reasons for having children that were other-oriented, like the desire to give to someone else, because even these "used" a child as a means to the woman's ends and thus were still ultimately seen as "selfish." The latter group of women believed that a good/right decision to have a child was motivated by the needs/desires/interests of that particular child: a child who did not yet and might never exist. Most women's condemnation as bad/wrong self-oriented reasons for having children, coupled with the difficulty a number faced in articulating a reason for motherhood grounded in the needs/desires/interests of their as-yet-unconceived child, goes a long way to explaining the difficulty women in the study had articulating good/right/rational reasons deciding to mother.

Another explanation would see "bad/wrong" reasons divided into two broad groupings. The first reflected the "good" motherhood requirements to which women subscribed and thus were "bad/wrong" because they failed to express the feelings and desires of "good" mothers. For instance, women's condemnation of a decision to have a child "when you don't really want one" or "to quell boredom" is really just the flip side of the requirement that "good" mothers be "enthusiastic" about having a child. The second grouping of "bad" reasons, like "to stay in step" or "to avoid loneliness in old age," were those that were socially normative until the late 1970 s or early 1980 s. ${ }^{14}$ Changed social attitudes towards the obligations inherent in the parent/child relationship, marriage and divorce, women's roles and the role and importance of individual decision-making in determining a person's life course or "biography"15 have undermined, if not discredited these reasons in the eyes of contemporary women. 
On the one hand, then, the data suggests the persistence of beliefs about "good" motherhood. Indeed, it is arguable that rising rates of female workforce participation over the past decades have rendered such ideals even more oppressive to the vast majority of women considering motherhood. On the other hand, the data demonstrate the success of feminist efforts to redefine motherhood as a "choice." Thus, at the same time that it is harder than ever to be a "good" mother, it is easier than it has ever for women to avoid motherhood altogether. It is perhaps not surprising that these two opposing trends have led increasing numbers of western women to delay or forgo motherhood.

Of course, social ideologies and norms are not the only influence on some women's perceptions that motherhood makes little sense. Women read about, perceive and are told by colleagues, sisters and friends about the practical conflicts motherhood poses to paid employment and/or career advancement. ${ }^{16}$ Pregnancy-based discrimination, inadequate or non-existent paid maternity and paternity leave, job insecurity and problems accessing affordable high quality child-care are among the obstacles many childless/childfree women are aware they will face if they decide to mother. In addition, the data suggest that most women assume that the "hard work" of caring for children was women's work. Whether they envisaged themselves assuming a "traditional" maternal role or juggling maternal responsibilities with and other pursuits, women assumed that they - not their male partners would be forced to negotiate and resolve the new life challenges presented by parenthood. ${ }^{17}$ This suggests that, even with no changes to existing social ideologies and norms around motherhood, it is likely that more women would find "good/right" reasons to mother, and motherhood a "rational" choice, if it was less difficult and more equitably distributed work.

Q2: How did the women define "good/bad," "right/wrong" and "rational/irrational," and how do their understandings accord with various philosophical and ethics understandings of these terms?

While some of the women justified their categorisations of reasons both for and against 
motherhood and childless/childfreeness/childfreeness as "good/right" in consequentialist terms, the vast majority did not. Jocelyn's belief that it is wrong for women to have children to satisfy a desire to "do it all" comes from her view that this sort of mothering has bad consequences for the woman's children. However, Laney's belief that it is wrong to bring a child into the world to satisfy her own needs seems to be speaking more to the question of the right or wrong motives for deciding to mother. Indeed, for most of the women, the goodness/rightness or badness/wrongness of particular reasons seemed to turn on the quality (high-mindedness/low-mindedness or seriousness/triviality) and type (self or other-centred) of the motives that inspired them. ${ }^{18}$

This was not the case for the few women who concluded that a decision to parent was irrational. These women's conclusions focused on the negative practical consequences of the decision. In specific, these women were concerned about the perceived disruption childbearing would have to two value sets or ideals: that of the "pure relationship" and the "economic rationalist."

\section{Pure Relationship}

Giddens describes the "pure relationship" as one that is "free-floating" (meaning that it is not weighted down by family obligations, restrictions of expectations) and contingent, in that is maintained only as long as both partners are satisfied. Within it, couples experience "confluent love," which is based active, contingent and based on mutual trust and commitment although not necessarily sexual exclusivity. ${ }^{19} \mathrm{~A}$ number of women in the study had experienced a long and chequered history with men, and were in their late thirties before they found men with whom they wanted to be in a permanent relationship. A number spoke at length about how much they valued their partners and about their joy at finally discovering themselves in a permanent relationship with what Barbara calls "the man of my dreams." When such women consider children, their potential impact on their marriage-like relationship looms large.

For some women, it was "irrational" - that is, not the best means for accomplishing their ends 
- to disrupt and potentially destroy an existing and valued relationship with a partner for the uncertain benefits of a relationship with an unknown child. Parenthood was deemed irrational because children were seen to pose an obstacle to men and women's best chance of finding intimacy by impeding their "achievement" of confluent love and a pure relationship, while relationships with children were seen as "unimportant or insignificant to social and intimate life". ${ }^{20}$

\section{Economic Rationalist}

Economic rationalism is an Australian shorthand used to describe government, corporate and individual attitudes and decision-making that prioritises the self-interested economic values and goals of businesses and "consumers" over all other national and individual ideals. Childbearing was seen by a large number of women as disruptive to their achievement of financial gain, and their independent and autonomous pursuit of the comforts and leisure time it provided. Many women believed that such pursuits could be at the centre of a justifiable description of "the good life," even if it was not the life they were sure they would pursue. For other women, it was the constraints motherhood would put on their capacity to choose if and when they would pursue a particular activity that made it seem an irrational choice to make. A third group of women saw a decision to mother as making little sense because they saw a rational decision as - by definition - one that maximised their self-interested aims.

The equation of self-interest and rationality should not be surprising, given the dominance of the "rational choice" explanations of political behaviour (which assert that human behaviour is predominantly or solely motivated by self-interest and only self-interested behaviour is rational) since the end of World War $1{ }^{21}{ }^{21}$ In contrast to formal and intimate relationships they had experienced with adults, the women perceived that the parent child relationship lacked sufficient flexibility to enable them to privilege their own needs and interests when they became pressing. As Barbara notes, her clients needs come first but in a pinch, her responsibility to them could be mitigated by "cancel[ling] the appointment." Because like other women in the study, Barbara's defines motherhood as a role in which she must always put 
her child's needs first, she sees a voluntary decision to engage in such an other- rather than self-interested relationship as irrational by definition.

Women's description of motherhood as an "irrational" choice also seemed to refer to some formal aspects of the childbearing decision. Many of the women shared common widely held philosophical beliefs that rational decisions are those based on reasons that can be conceptualised, articulated and compared. They are ones consistent with past decisions, and are made by detached decision-makers logically weighting up the facts. ${ }^{22}$ As Sharon's lopsided list of pros and cons demonstrates, decisions about motherhood seemed to lack these formal qualities. Consistency has also been a hallmark of the thin theory of rationality. ${ }^{23}$ Hence, part of what seems to lead Barbara to conclude that a decision to mother is irrational is that it would be a decision that embraces all the values she has long rejected; those associated with predicability and permanence.

Q3: Why should philosophers be concerned about some women's negative conclusions about the rationality ${ }^{24}$ of deciding to mother?

I believe applied philosophers should be concerned about women's negative conclusions about the rationality of deciding to parent for four reasons. I present them in reverse order of importance.

Declining fertility has an accelerating negative impact on the lives of existing mothers and children

Declining fertility rates can be seen, at least in part, as a consequence of women's beliefs about the rationality of deciding to have children. Declining fertility rates have a dramatic and accelerating impact on total population levels. To keep the birth and death rate balanced; the birth rate needs to be maintained at the "replacement level" of an average 2.1 babies per woman. If women have, on average, only one child, population levels will halve in the size of just one generation (around 28 years), and in two generations (56 years) will decline to a quarter of the previous level. ${ }^{25}$ 
McDonald argues that an unrecognised consequence of rapid declines in population rates brought about by declining fertility (even in countries where reduced populations would probably be a good thing) is its impact on choice and cultures:

Sustained very low fertility is not the way to achieve the goal of population decline because of the disruptions that are caused to society...Sustained very low fertility will change cultures. In particular, the place of children in the culture will be minimised and social institutions will adapt to the relative absence of children. A subsequent reversal of this trend would be difficult and slow. ${ }^{26}$

In addition, when future populations have many more people aged 75 and over than aged 20 and under, there are insufficient financial and manpower resources to care for older citizens. He argues that increased migration is an ineffective way of slowing down the rapid aging of the population caused by low fertility unless the intake is massive, and that foes of immigration in most developed countries oppose the intake numbers necessary. ${ }^{27}$

Declining fertility represents, in significant part, women's lack of full reproductive freedom

While infertility is seen to account for approximately 7 per cent of current and predicted childless/childfreeness in Australia and the United States, the remainder of this childless/childfreeness is uniformly described as "chosen". ${ }^{28}$ The accuracy of such a description is doubtful insofar as it suggests that the childless/childfreeness of all fertile women is expected, desired and voluntary. Surveys of the childbearing intentions of young Australian and North American women repeatedly reveal the intention of approximately 92 per cent, respectively, to mother. Most intend and desire to bear at least two children, with only 2 per cent of the Australian public believing that having no children or only one child was ideal. ${ }^{29}$ In countries where attitudinal and institutional policies support working parents to fulfil both their work and domestic responsibilities (most notably the former German Democratic Republic and the Nordic countries), the fertility levels women achieve come closer to the fertility levels they intend, and fertility rates overall remain relatively high. However, in countries with attitudes and practices antagonistic to working women (most notably Italy), fertility is low. ${ }^{30}$ The statistical suggestion that many fertile women are childless/childfree by 
circumstance rather than choice is supported by the largely unacknowledged findings of the majority of social research conducted since 1975 on this issue.

What such smaller and larger-scale findings strongly suggest is that women's freedom to decide when and whether to mother is being constrained by social forces and factors outside their direct control. Significant feminist effort has gone into fighting laws and policies that constrain women's freedom to avoid motherhood, and into ensuring the availability of the products and services necessary for women to put their decisions to defer or forgo motherhood into effect. This effort was right and necessary, and the freedoms most women now exercise in Australia and North America to avoid or to terminate unwanted pregnancies have been hard fought and remain in contention. ${ }^{31}$ Constraints on women's capacity to choose, rather than to avoid, motherhood are not largely the result of legal or policy restrictions on women's freedom to become and remain pregnant, although some groups of women do face such difficulties. Rather, they are a consequence of ongoing inequality between the sexes and a lack of positive attitudinal and structural support for all - but particularly working - parents. Petchesky argues that it is these "social and material conditions" that ought concern feminists, not the "context of women's choices, or even the 'right to choose'” ${ }^{32}$ While feminist philosophers have traditionally been more concerned about women's incapacity to avoid rather than embrace motherhood ${ }^{33}$, all philosophers ought rightly be concerned with the constraining influence of social and material conditions on women's reproductive freedom regardless of whether the outcomes of such constraints are forced motherhood or forced childless/childfreeness.

Philosophers bear some causal and moral responsibility for women's view that a decision to mother is irrational while a decision to remain childless is irrational

Philosophers bear some degree of causal as well as moral responsibility ${ }^{34}$ for women's negative assessment of the rationality of motherhood. This is because women's belief that having children is an irrational, and childlessness a rational, choice has arguably been influenced by arguments put forward by feminists and childfree advocates that cast doubt on the moral agency, rationality and even the intelligence of those who decide to parent. These 
arguments have flourished in an environment in which the claims of childfree advocates have remained unanalysed by philosophers and old reasons for having children have been discredited but few contemporary normative accounts of the parenthood decision have surfaced to replace them.

Philosophers and other theorists have failed to respond to this vacuum created by the demise of longstanding "god" reasons for having children. Indeed, as Smilansky noted in a 1995 Journal of Applied Philosophy article entitled "Is There a Moral Obligation to Have Children?", non-feminist philosophers have largely ignored the question of whether individuals and/or couples ought to have children. ${ }^{35}$ This has most likely been for two related but opposing reasons. For some orthodox philosophers, parenthood in general and motherhood in particular has been seen as "natural," the outcome of human "instinct" rather than reason and thus legitimately outside the concerns of moral philosophy. ${ }^{36}$ More recently, orthodox philosophers may have chosen to give the question, "why have children?" wide berth because of feminist sensitivities regarding accounts that oblige women to forfeit their reproductive autonomy for the greater good or re-conflate womanhood with motherhood (and thus exclude childless women). ${ }^{37}$

In contrast to their non-feminist colleagues, Feminist philosophers have evinced considerable interest in questions like "should women mother?" and "why, given the oppressive nature of motherhood, do women desire and pursue motherhood?" However, the preponderance of answers given to the former question have been in the negative, while explanations for the latter have contended women are victims of pronatalist ideologies that have robbed them of any real choice about desiring or deciding to mother ${ }^{38}$. While this claim, largely made in relation to infertile women's decisions to use Assisted Reproductive Technologies [ARTs] has been soundly discredited, none of these critiques have defended the rationality of women's decisions to become mothers. ${ }^{39}$ Further, prominent feminist philosophers have continued to question the capacity of any woman, not just those who are infertile, to make an autonomous decision to mother. ${ }^{40}$ 
The increasingly voluminous "childfree" literature also questions the agency, rationality and even intelligence of those who decide to have children while simultaneously lauding these qualities in the decisions of the childfree. From the early days of the childfree movement until today, childfree advocates argue that the pressures of pro-natalist societies mean most people become parents under duress, without consciously deciding to do so on the basis of "good" reasons. ${ }^{41}$ In contrast to such mindless "breeding," the childfree describe themselves as having made an active conscious choice to be childfree, often in the face of unrelenting social pressure. ${ }^{42}$ The bulk of childfree discourse, however, focuses on promoting the childfree decision as a more rational and intelligent one than a decision to become a parent: a view encapsulated by the self-ascribed acronym for the childfree THINKERS (Two Healthy Incomes, No Kids, Early Retirement).$^{43}$ Since the early days of the movement, childfree advocates have promoted the childfree lifestyle as more rational because it enables the pursuit of a more economically rationalist, dyadically intimate and environmentally responsible lifestyle: one that is responsibility-, commitment-, and risk-reduced. In addition, they have praised the rationality of those who avoid children because they fear childbirth or lack confidence in their capacity to parent competently or well. Those, to use the words of a woman in the current study, who fear they are "unequal to the task". ${ }^{44}$ Thus, in some parts of this discourse, rationality is conflated with self-interest, and a decision to parent is seen to be irrational because it is other- rather than self-oriented. In other parts, irrationality is equated with risk-taking in which the odds of the risk not paying off are extremely high. For example, Moore and Moore argue that:

Having children is an enormous undertaking. There are so many things to think about, so many things you can't predict, so many things that you can't guarantee, so much to learn, so much to do, such a long-term commitment and, at the end of it, you have to let them go. ${ }^{45}$

Having argued that those who have children risk a significant toll on the a pursuit of selfinterested goals, and that the likelihood of this risk being incurred is very high (if not inevitable) childfree advocates conclude that only those who are "stupid" have and will continue to have children. ${ }^{46}$ 
The goals of the childfree movement are consistent with their analysis of the problem of the parenthood decision. Firstly, they hope to promote the agency of those of reproductive age by encouraging them to make a deliberate decision about whether to have children. However, in promoting prospective parents' agency, many childfree believe they are simultaneously supporting the making of more rational decisions about children because most believe that deliberation on the childbearing question will force the conclusion that parenthood is an irrational choice to make. This is because, according to Moore \& Moore, there are no "...good rational reasons for having children."

The childfree movement also advocates the removal of what they describe as economic and workplace discrimination against the childless. Many in the childfree movement resent their taxes going to infrastructure or services - like schools and hospitals - that they never use, or use less often than those with parents. ${ }^{47}$ The claim is that those with children are selfishly using childfree people's taxes and unfairly imposing on them in the workplace. Says Nankivell:
"Equal pay for equal work" was once the proud demand of the feminist movement. But like the pigs in Animal Farm, these days some women (and some men) seem more equal than others. Those with their snouts in the trough are working parents who, under the guise of family-friendly policies are demanding - and receiving - special treatment...The fundamental inequity arises from the privileges working parents receive at the expense of their childless colleagues. ${ }^{48}$

The data suggest that such accounts, which imply that childlessness is the only decision an agent acting autonomously, rationally and intelligently could make, contribute to some women's decisions to delay or avoid motherhood. As well, it suggests the possibility that some women might make different decisions about parenthood were there more balance in available normative accounts of the parenthood decision.

Many of the reasons women give for having children and being childfree are ones that provide answers to the "what sort of person should I be" and "how ought I to live?",49

The reasons women in the study gave for desiring/deciding to have children or to remain 
childless/childfree have already been presented. These reasons do not support some women's conclusions that it is irrational to decide to have as child. Instead, they suggest possible answers to the question of how a person ought develop themselves and live in order that they be considered a virtuous person engaged in the project of living a moral life. This is not to say that all the reasons on either list should be included in normative accounts of the decision to have children or be childless: some may be too lacking in moral agency or virtue for inclusion. ${ }^{50}$ Rather, it is to point out many of the reasons people have for desiring and pursuing parenthood are those that explain why, for them, having children is a way of developing themselves and living a good life. In the same way, some of the reasons people have for not having children explain why for them, being childfree is a way of developing themselves and living a good life. The point is that there is more than one way to develop oneself and to live a good life. Having and parenting children is an important - but only one of these. Held addresses this point when she says, "Men (and women) can die out of loyalty, out of duty, out of commitment, and they can die for a better future. Women can give birth, or refuse to give birth, from all these motives and others". ${ }^{51}$

Q4: What might a normative account of the decision to parent, acceptable to both feminist and non-feminist philosophers, include and avoid?

It is beyond the scope of this paper to develop a complete normative account of the decision to parent. However, the data and above analysis suggest some requirements for such an account if it is to speak successfully to women's concerns and avoid the problems feminists nominate as risks inherent in the undertaking of such a project.

1. A normative account of the rationality of the childbearing decision should include the requirement that women consider parenthood and childlessness as a decision that must be made on the basis of good reasons. ${ }^{52}$ In an era of contraception and legal abortion, motherhood and childlessness are decisions most women are able to, and believe they must, actively choose. Indeed, the current data supports numerous studies that suggest that the decision whether or not to have children, rather than the motherhood experience 
itself, is a contemporary female rite of passage. ${ }^{53}$ This view of how decisions ought to be made is consistent with both commonsense and philosophical accounts of rational, or what Held calls, "distinctly human" decision-making. ${ }^{54}$

2. Reasons for having children that involve the desire to nurture or share with or give to a child must be clearly established as moral ones for childbearing. Gibson's analysis suggests that the concerns women expressed in this area were grounded in anxieties that having a child to satiate their own desires - even altruistic ones - is wrong because they would be using the child as a means to their ends. The solution she proposes requires close attendance to the categorical imperative which states that we never treat other people "simply as a means, but always at the same time as an end." Thus reasons for having children, like the desire to nurture, share or give to her, would be good ones because while they treat the child as a means to an end, they do so in a way that is "compatible with treating them at the same time as an end." 55

3. Self-interest and rationality should neither be conflated, nor held to be unrelated. An account of the rationality of having children must oppose the conflation, in economic and childfree discourses, of self-interest and rationality. Mansbridge argues that humans are innately motivated by both self-interested as well as altruistic and unselfish motives like love and duty ${ }^{56}$. The naturalness of acting for others suggests that humans incur a cost associated with being unable to express and act from non-self-interested motives. However, people are more likely to act in altruistic and unselfish ways if the cost to their self-interest is not too high. This suggests that alongside arguments that women are harmed by the denial of opportunities to express and act - through a decision to mother and through consequent maternal practice - from altruistic motives, philosophers must (continue to) protest as unacceptable the unnecessary and unequal sacrifices currently demanded of contemporary mothers.

4. Further analysis and critique of the pure relationship construct needs to be undertaken. In particular, and as identified by Smart ${ }^{57}$, the empirical and normative validity of the pure 
relationship construct must be questioned and the parent-child relationship included in any complete account of intimacy.

All of these suggestions could be followed without fear of violating the feminist injunction that normative accounts of the decision to have children must avoid making childbearing a moral obligation or even what Smilansky calls a "moderate inclining moral consideration." Following them would also not lead to the re-conflation of womanhood and motherhood, and the consequent exclusion of childless women. To make doubly sure of this, I would recommend that normative accounts of the decision to have children be constructed in nongender specific ways, insofar as this is possible ${ }^{59}$

\section{POSSIBLE OBJECTION}

It may seem that my account is vulnerable to charges of imbalance and inconsistency. This is because I do not insist that, alongside work on normative accounts of the decision to parent, philosophers also begin work on normative accounts of the decision to be childfree. Does this not undermine my argument that rational decisions can be made both to have children and to be childless? Mightn't it also lead to just the sort of imbalance in available accounts, and the negative impact on decision-making, that l've suggested is currently the case, only this time in favour of normative accounts of the decision to parent?

I believe not. The data suggest that women find it easy to marshal good reasons to avoid having children and difficult to find good reasons to have them. This is part of why they believe it is the decision to have children, not to be childfree, that is irrational. I have argued that this finding is related to the promulgation in the last thirty years, by feminists, social theorists and childfree advocates, of normative accounts of the decision to be childfree. The message of such accounts is consistent with and supported by dominant economic and relationship values. I would agree that it is important that normative accounts of the decision to have children and to be childfree exist. However, the shortage of the former - and the resultant undermining of the rationality of decisions women make to mother - make it 
important for philosophers to focus on creating normative accounts of the decision to parent until some discursive balance is restored.

\section{NOTES}

${ }^{1}$ [Barnes, 2001 \#574][Qu, 2000 \#570] [McDonald, 1998 \#414][McDonald, 1997 \#459]

${ }^{2}$ The findings on this question, which have and will continue to be reported elsewhere, revealed that while a small portion of the sample were "childless/childfree by choice," the majority described themselves as "childless/childfree by circumstance" [See ICannold, 2001 \#572].

${ }^{3}$ [Australian Bureau of Statistics, 1999 \#579][Heaton, 1999 \#575]. [More detail about the study can be found in ICannold, 2000 \#621].

${ }^{4}$ [Smiley, 1998 \#521][Maushart, 1997 \#130][Eyer, 1996 \#323][Kennison, 1996 \#295][Brown, 1994 \#238][Swigart, 1991][Richards, 1985 \#80][Chesler, 1979 \#490][Rich, 1976 \#87]

${ }^{5}$ [Cannold, $2000 \# 573$ ]

${ }^{6}$ All the women in the study had both positive and negative desires regarding children. The reasons discussed in this section were those women both inclined towards and against parenthood gave for why they wanted/decided to have children or to be childfree.

${ }^{7}$ [Cannold, $2000 \# 621$ ]

${ }^{8}$ [Cannold, 2000 \#621]

${ }^{9}$ [Gibson, 1995 \#613, 234]

${ }^{10}$ [Bryson, 1998 \#390][Wicks, 1998 \#197][Bulbeck, 1997 \#126][Lumby, 1997 \#35][Marshall, 1989 \#99]

${ }^{11}$ [Kaplan, 1996 \#110]

${ }^{12}$ [Gibson, 1995 \#613]

13

${ }^{14}$ [Gilding, 1991 \#173][Richards, 1985 \#80](Veevers, 1980)

${ }^{15}$ [Beck, 1995 \#232, 5]

${ }^{16}$ [Cannold, 2000 \#576] 
${ }^{17}$ This expectation is well in-line with reality. Countless studies suggest that Australian and American women continue to shoulder the majority of domestic and childcare work, although in relative terms women's contribution is decreasing while men's contribution is marginally increasing [Maushart, 2001 \#599, chapter 7][de Vaus, 1997 \#598]. Mothers are also the parent more likely to work part-time, particularly in Australia, or to withdraw from paid employment altogether when children are young [Glezer, 1997 \#597].

${ }^{18}$ This confirms the findings of previous research which found that women's evaluation of the morality of abortion centred around the particular women's motives, behaviour, emotions and decision-making process, rather than on the question of whether she had the right to terminate or whether the termination would maximise utility [Cannold, 2000 \#57, xviii].

${ }^{19}$ [Giddens, 1992 \#199; Giddens, 1991 \#132]

${ }^{20}$ [Smart, 1997 \#254, 313]

${ }^{21}$ [Mansbridge, 1990 \#592]

22 [Gatens, 1998 \#602][Rooney, 1994 \#583][Ruddick, 1989 \#240][Williams, 1985 \#582]

${ }^{23}$ [Elster, 1983 \#594]

${ }^{24}$ In the remainder of this paper's arguments, I will take as the central concern at issue women's negative conclusions about the rationality of the motherhood decision, even though only a few women in the study directly labelled this decision as "irrational." This is because the vast majority of women in the study believed that a decision to parent should be made for reasons and that these reasons be good/right ones. Further, most held that there were few or no good/right reasons to have a child. Thus it seems plausible to assume that many more than volunteered the label "irrational" would accept it as an accurate description of their evaluation of the decision to parent because of the majority's belief that it would not be rational to make a decision to parent on the basis of bad/wrong reasons.

${ }^{25}$ [McDonald, 1998 \#414, 3]

${ }^{26} \mathrm{He}$ argues that if reduced populations are desired, they can be achieved without major social disruption by sustaining a fertility rate at slightly under replacement level. [McDonald, $1998 \# 414,3]$

27 [McDonald, 1998 \#414, 1] 
${ }^{28}$ [Australian Bureau of Statistics, 1999 \#579](McDonald, 1998b)

${ }^{29}$ (Callan \& Noller, 1987, 9; Caron \& Wynn, 1992; McDonald, 1998a; Young,

1996)(Vandenheuvel, 1991, 11)

${ }^{30}$ [Barnes, 2001 \#574](Chesnais, 1996; Finzel, 1999; McDonald, 1997; McDonald, 1998a)

${ }^{31}$ [Cannold, 2000 \#573]

32 (Petchesky, 1985, 11)

${ }^{33}$ [Shanner, 1998 \#595][Parkes, 1999 \#453, 89][Berg, 1995 \#578]

${ }^{34}$ For an account of the distinction between causal and moral responsibility see [Mackenzie, 1995 \#620]

${ }^{35}$ [Smilansky, 1995 \#614, 42]

${ }^{36}$ [Held, 1993 \#581]

${ }^{37}$ [Smilansky, 1995 \#614, 51][Held, 1993 \#581][Ruddick, 1989 \#240]

${ }^{38}$ [Snitow, 1992 \#209] [Rich, 1976 \#87][de Beauvoir, 1952 \#604]

${ }^{39}$ [For examples of ART literature in which feminists make these claims see \Rowland, 1993 \#217][Rowland, 1987 \#606][Spallone, 1987 \#607][Arditti, 1984 \#31][Corea, 1977 \#605]. [For arguments discrediting these claims see \Albury, 1999 \#456][Charlesworth, 1995 \#580][Birke, 1990 \#113][Purdy, 1989 \#618]

${ }^{40}$ [Meyers, 2001 \#619]

${ }^{41}$ [Veevers, 1980 \#421][Moore, 2000 \#566]

42 [Belkin, 2000 \#564][No Kidding, 1999 \#435][Lisle, 1996 \#545][Morell, 1994 \#86][Veevers, 1980 \#421]

${ }^{43}$ [Belkin, 2000 \#564, 32]

${ }^{44}$ [See, for example Moore, 2000 \#566][Mclntosh, 1999 \#357][Safer, 1996 \#29][May, 1995 \#85, chapter 6]

${ }^{45}$ [Moore, $2000 \# 566$ ]

${ }^{46}$ [Moore, $\left.2000 \# 566,82\right]$

${ }^{47}$ [Belkin, 2000 \#564][Moore, 2000 \#566][Childless by Choice, 1999 \#405]

${ }^{48}$ [Nankivell, 2001 \#615] 
${ }^{49}$ I am indebted to Janna Thompson for suggesting and assisting me in pursuing this line of argument.

${ }^{50} \mathrm{I}$ am thinking here of reasons for having children that refer to the desire to fit in with others, to fulfil eugenic population ideals and reasons for being childfree that are based in insecurity in one's capacities to parent well and an aversion to sharing adequate financial resources.

${ }^{51}$ [Held, 1993 \#581, 117]

52 The data suggest this is a requirement that the majority of women are already fulfilling.

${ }^{53}$ [Ziman Tobin, 1998 \#412][Mackay, 1997 \#237][Faux, 1984 \#55]

${ }^{54}$ [Held, 1993 \#581, 112][Gibson, 1995 \#613]

${ }^{55}$ [Gibson, 1995 \#613, 236]

${ }^{56}$ [Mansbridge, 1990 \#593]

${ }^{57}$ [Smart, 1997 \#254]

${ }^{58}$ [Smilansky, 1995 \#614, 51]

${ }^{59}$ I suspect this will not be entirely possible because of the need to include in any account of the decision to mother reasons to do with pregnancy, birth and lactation. 


\section{University Library}

\section{- M M N E R VA A gateway to Melbourne's research publications}

Minerva Access is the Institutional Repository of The University of Melbourne

Author/s:

CANNOLD, LESLIE

Title:

Do we need a normative account of the decision to parent?

Date:

2002

Citation:

Cannold, Leslie (2002) Do we need a normative account of the decision to parent?

Persistent Link:

http://hdl.handle.net/11343/33710 